\title{
CHANGES OCCURRED IN A PORCELAIN FACTORY DUE TO QUALITY MANAGEMENT SYSTEM IMPLEMENTATION
}

\author{
Adina Sârb ${ }^{1 *}$, Liliana Itul $^{2}$, Maria Popa ${ }^{3}$ \\ ${ }^{1}$ Doctoral School, Faculty of Engineering, Lucian Blaga University of Sibiu, Romania \\ ${ }^{2}$ Quality Department, S.C. Apulum S.A., Alba Iulia, Romania \\ ${ }^{3}$ The Business Administration and Marketing Department, Faculty of Economic Science, "1 \\ Decembrie 1918" University of Alba Iulia, Romania \\ sarb.adina92@yahoo.com \\ liliana.itul@apulum.com \\ mariapopa2010@yahoo.com
}

\begin{abstract}
The issues approach in this research show the benefits of the implementation of ISO 9001 standard in different companies as well as the importance of certain criteria with respect to customer satisfaction and confidence. This standard specifies requirements for a quality management system and it is based on a number of quality management principles including a strong customer focus, the motivation and implication of top management, the process approach and continual improvement. The criteria taken into account help to improve the quality management system of the organization. The purpose of this paper is to identify the changes due to the implementation of a quality management system based on ISO 9001 standard in a porcelain factory, named S.C. Apulum S.A. and to analyse the customer satisfaction and confidence within the company considered through the implementation of the standard mentioned above. The analysis of customer satisfaction and confidence was achieved by taking into account certain measurable criteria established in the company considered, criteria that have been introduced into a formula. In conclusion, it is obvious that after the implementation of the requirements of ISO 9001 standard the situation regarding the quality process and product has been improved considerably. Also, the results show that there were several variations in the period considered (2010-2017).
\end{abstract}

Keywords: Quality Management System, ISO 9001, customer satisfaction, porcelain factory.

JEL classification: L00, L15.

\section{Introduction}

According to BS EN ISO 9000:2015 (The British Standards Institution, 2015) we can retain a definition for quality management system (QMS) as "QMS can be considered as a set of Policies, Procedures, Processes and resources used to achieve the organization objectives and desired results, by manages the interacting processes, resources required and inter-related parts of the business, which enables top management to best use the available resources considering the long and short term consequences" (Refaat and El-Henawy, 2018). A QMS covers a broader range of activities than quality control and quality assessment by including both technical and management requirements (Carey, 2018). Also, it is an imperative of progress and a tool for the development of any factory, regardless the field of activity. Companies "have been forced" to open their doors to the culture of quality,

\footnotetext{
* Corresponding author: Adina Sârb
} 
which is often associated with the international management standard - ISO 9001 (Santos et al., 2012).

ISO 9001 describes the requirements of a QMS that needs to be implemented consistently so that the companies can produce the products according to customer's requirements, achieve customer's satisfaction, and achieve continual improvement on the effectiveness of their QMS (Sumaedi and Yarmen, 2015). It can be applied in different kinds of organizations all over the world (Ingason, 2015).

There are lots of benefits resulting from the implementation of a QMS based on ISO 9001 in a company. The most important are: the opportunities for infiltration in new markets; global deployment; increase exportation; increase productivity; improve the company's image in the market; improve the quality of the products and/ or services; reduction of defective products; cost reduction and reduction of the customer audits. Also, there are other important aspects, such as: decrease the rate of incidents; non-conformities and complaints; increase the profitability; improve the use of time and resources; clear definition of responsibilities; improve the work environment; increase customer's satisfaction and confidence; improve the understanding of customer's needs and expectations; increase sales (Santos et al., 2012; Priede, 2012; Aggelogiannopoulos et al., 2007).

In order to evaluate the effectiveness of the QMS and to gather information about working processes and how the organization accurately applies the policies and procedures, audit activities have to be applied. Also, they are useful to identify opportunities for improvements, which are critical to the success of an organization. During the audit tangible and intangible evidence needs to be collected, in addition, corrective and preventive actions can be taken according to the evidence gathered, therefore the quality audit can be consider as a key element and an important part of applying QMS.

We can define quality audit as systematic, independent and documented process of examining the QMS. These processes can be done by an internal or external quality auditor or by an audit team according to the organization size (Refaat and El-Henawy, 2018).

According to the International Organization for Standardization (ISO), as shown in Figure 1. there are seven Quality Management Principles (QMP) which are: QMP1: Customer focus, QMP2: Leadership, QMP3: Engagement of people, QMP4: Process approach, QMP5: Improvement, QMP6: Evidence-based decision making, QMP7:Relationship management. These principles are not listed in priority order. The relative importance of each principle will vary from organization to organization and can be expected to change over time (Refaat and El-Henawy, 2018).

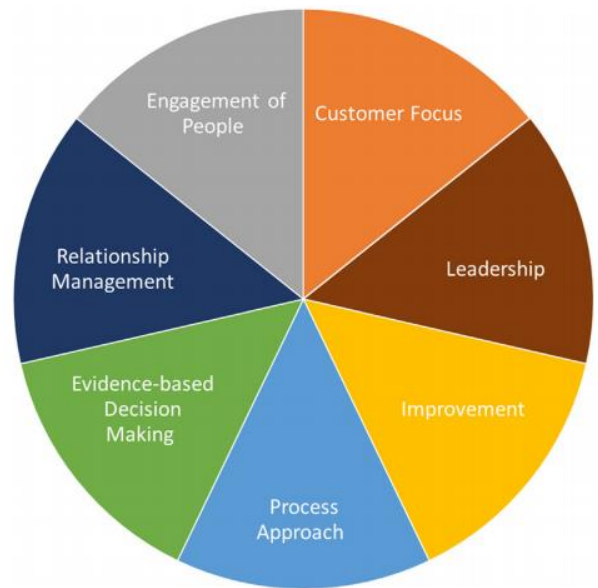

Figure 1: Quality management principles Source: Refaat and El-Henawy, 2018 
ISO 9000 series of international standards introduced the process approach as the base for better understanding requirements and to assist organizations in establishing their QMS. To have a clear understanding, it is recommended to define a process which is known as a set of interrelated or interacting activities, which transforms inputs into outputs. These activities require allocation of resources such as people and materials. In Figure 2 ISO 9000 illustrates a generic process for further understanding. The model of a process based QMS shown in Figure 2 illustrates the way organizations should manage numerous linked activities in order to function effectively to produce the required output (Magd and Nabulsi, 2012).

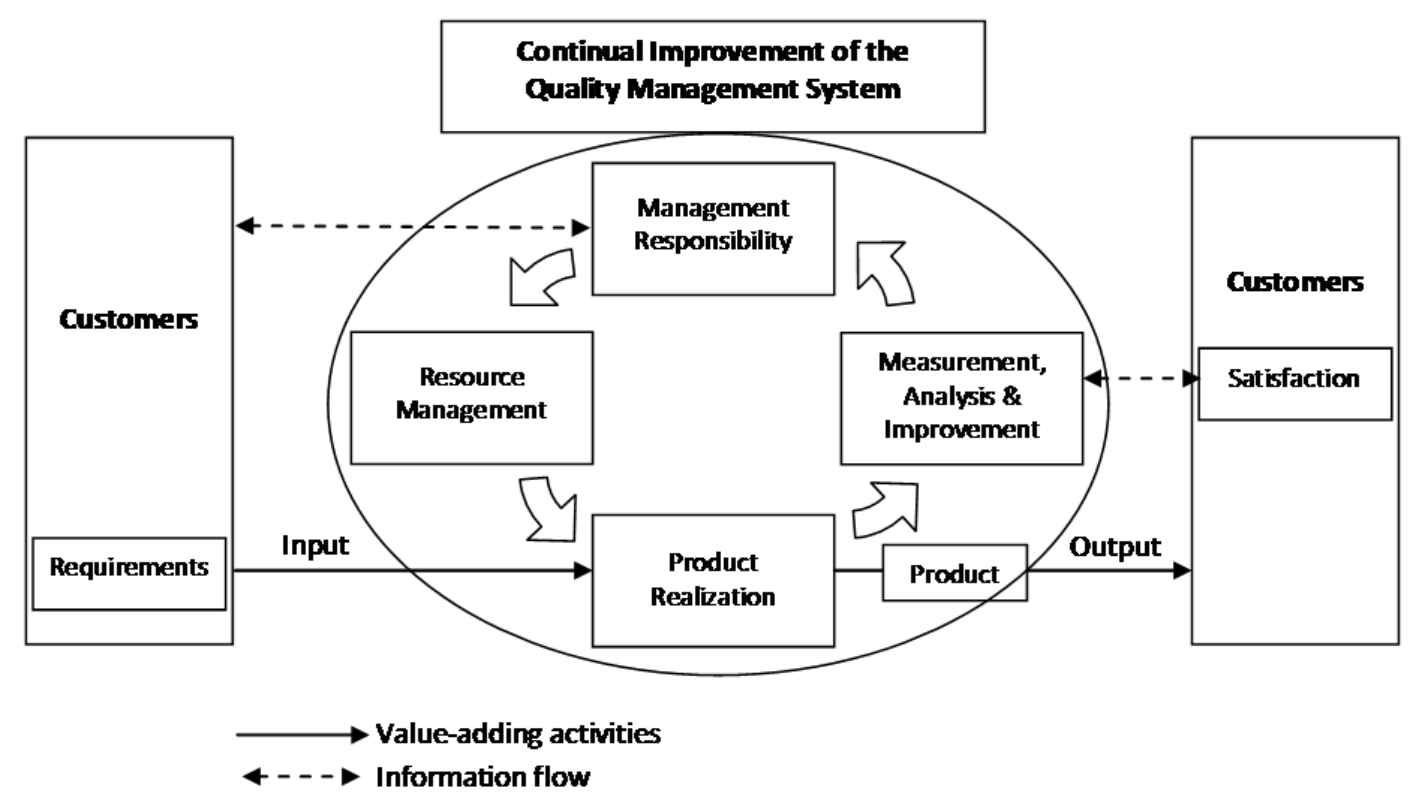

Figure 2: Model of a process - based Quality Management System

Source: SES Quality

This paper approaches a study case which contains in the first stage the changes occured as a result of implementing the requirements of a QMS in accordance to ISO 9001 in S.C. Apulum S.A. and in the second stage the degree of customer satisfaction and confidence in the company considered.

\section{Presentation of the S.C. Apulum S.A. Company}

The company considered in the case study is S.C. Apulum S.A., it was founded in 1970 in the city of Alba lulia. It is the largest porcelain manufacturer in Romania and also in South-Est Europe, with a variety of production:

- household and HoReCa articles on porcelain;

- decorative objects;

- frills.

Credibility of the "Apulum" results from the main strengths of the company, such as:

- quality of raw materials;

- modern technology used to manufacture different products;

- staff structure;

- the price-quality ratio perfectly adapted to the customer`s requirements; 
- modern and dynamic management, adaptable to the changes that may occur in the internal and external business environment.

Sustainable development of the company and its competitiveness are directly dependent on the proper functioning of the QMS. Certification of QMS according to ISO 9001 can help to maintain a long trusting relationship with consumers (Lukichey and Romanovich, 2016). Therefore, S.C. Apulum S.A. has implemented, certified and maintained, since 1998 until now, a QMS according to ISO 9001:1994. In 2017, the company was recertified in accordance to ISO $9001: 2008$ and in 2018 took place the surveillance audit with transition on ISO $9001: 2015$.

The requirements of the QMS reflect in the entire activity of the company, respectively logistics, production, quality control and commercial department (Apulum porcelain factory).

\section{Case Study}

The purpose of this research is to identify the changes occurred within the porcelain factory due to implementation of a QMS standard and in the same time to identify the degree of customer satisfaction and confidence in the company considered by using specific criteria in the activity field of S.C. Apulum S.A.

Following the implementation of ISO 9001 in the company considered, the company's problems regarding both the quality processes and products have been improved. Figure 3 shows the situation before and after implementation of ISO 9001.

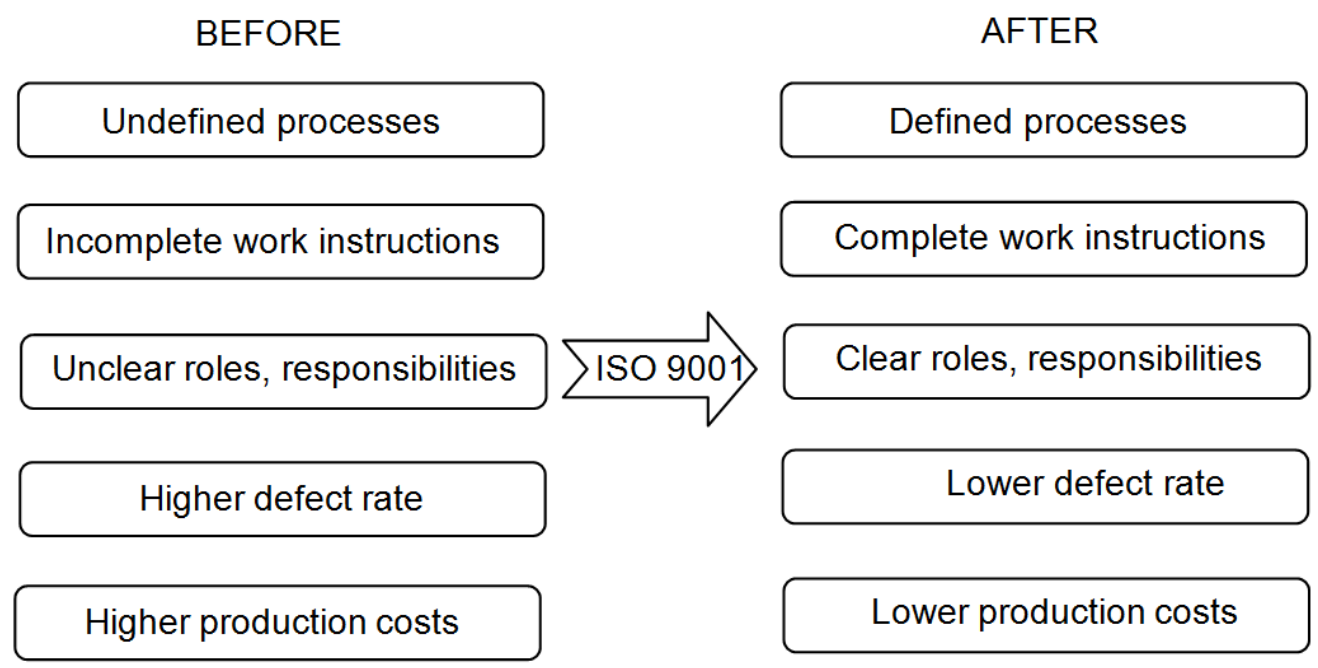

Figure 3: The situation before and after implementation of ISO 9001 in S.C. Apulum S.A.

Figure 3 illustrates that the changes occured after the implementation of the requirements of ISO 9001 standard have led to the improvement of the QMS in the organization. Therefore, defining processes and developing work instructions have caused the elimination of unnecessary stages from the processes, saving time and reducing costs within the company. Also, employee training was one of the measures implemented to reduce the defects of the products manufactured in the organization. Therefore, the improvement of the product quality is reflected in the company's economic situation, which has increased considerably with the implementation of the QMS.

The company's clients are both internal and external (Table 1), aiming their satisfaction and confidence during 2010 - 2017. The criteria taken into account in order to identify the degree 
of customer satisafction and confidence in the company considered, as well as their posibilities of interpretation are presented in Table 2.

Table 1: The most important clients of S.C. Apulum S.A.

\begin{tabular}{|l|l|}
\hline External clients & Internal clients \\
\hline IKEA & S.C. Servcom Imp. Exp. \\
\hline Rody Time Italy & S.C. Prod Gabi 2000 S.R.L. \\
\hline Fiskars Finland Oy & S.C. Metro Cash\&Carry \\
\hline Villeroy \& Boch Germany & S.C. Selgros Cash\&Carry \\
\hline Befas Greece & S.C. Dany S.R.L. \\
\hline Borras Spain & S.C. Pm Com S.R.L. \\
\hline Porsgrund Norway & S.C. Elemar Cadia S.R.L. \\
\hline Rosendahl Denmark & S.C. Sologvg S.R.L. \\
\hline Mimco & S.C. Maramold \\
\hline Ceramica Sant Pankrac Spain & S.C. Scodef Impex S.R.L. \\
\hline
\end{tabular}

The research methodology is based on brainstorming technique. It is one of the techniques for fostering group creativity by which ideas and thoughts are shared among members spontaneously in order to reach solutions to practical problems (Hosam \& Shuhaila, 2018). The term was popularized by Faickney Osborn in 1953 in the book titled "Applied Imagination" (Litcanu et al., 2015). Some researchers questioned the effectiveness of comparing group brainstorming technique with individual idea generation. However, to generate ideas solidarity is a challenging task because of the limit of individuals` experiences, knowledge and perspectives (Hsu et al., 2018).

In group creativity, the unique brainstorming rules introduced by Osborn are: the quantity is desirable, there is no criticism and the wildest ideas are welcomes, because combining them can lead to optimal solutions in order to solve problems. In this case, personality traits are one of the diversity that should be explored in group creativity (Zainol et al., 2012). Also, the essential ingredient to start brainstorming is that all comers have an equal input to the session (Krone, 2017).

The criteria applied in the study case as well as their possibilities of interpretation were chosen by using brainstorming technique. For this purpose, the moderator - C.A. chosen by the manager described the problem. Also, the manager selected the following participants: quality manager:I. L., production coordinator: C.A., chief of technical department and development:G. A., mills responsible: O. I., forming responsible: B. P., firing responsible: B. S., packing responsible: N. C. They received an invitation that contained the name of the meeting, the issue to be discussed, the date, the time and the place. Also, the moderator led the meeting and he ensured compliance with the rules established by Faickney Osborn. Table 2 shows the results obtained following the application of brainstorming technique. 
Oradea Journal of Business and Economics, Volume IV, Issue 1

Published on March 2019

Table 2: The criteria taken into account in order to identify the degree of customer satisfaction and confidence and their possibilities of interpretation

\begin{tabular}{|c|c|c|}
\hline \multicolumn{2}{|l|}{ Criteria } & $\begin{array}{ll}\begin{array}{l}\text { Possibilities } \\
\text { interpretation }\end{array} & \text { of } \\
\end{array}$ \\
\hline \multirow{3}{*}{\multicolumn{2}{|c|}{ Evolution of clients business }} & $\Delta>0$ \\
\hline & & $\Delta \approx 0$ \\
\hline & & $\Delta<0$ \\
\hline \multirow{3}{*}{\multicolumn{2}{|c|}{ Duration of colaboration }} & Over 10 years \\
\hline & & Over 7 years \\
\hline & & 0 years \\
\hline \multirow[t]{14}{*}{ Questionaire } & \multirow[t]{2}{*}{ Relationships with competing firms } & Yes \\
\hline & & No \\
\hline & \multirow{5}{*}{$\begin{array}{l}\text { Weight value of Apulum's products/ client } \\
\text { business }\end{array}$} & $100 \%$ \\
\hline & & $75 \div 100 \%$ \\
\hline & & $50 \div 75 \%$ \\
\hline & & $25 \div 50 \%$ \\
\hline & & $0 \div 25 \%$ \\
\hline & \multirow{5}{*}{$\begin{array}{l}\text { Client forecasts (Collaboration with } \\
\text { S.C. Apulum S.A.) }\end{array}$} & Very good \\
\hline & & Good \\
\hline & & Weak \\
\hline & & Very weak \\
\hline & & Without collaboration \\
\hline & \multirow[t]{2}{*}{ Advertising for S.C. Apulum S.A. } & No \\
\hline & & Yes \\
\hline \multirow{2}{*}{\multicolumn{2}{|c|}{ Complaints }} & No \\
\hline & & Yes \\
\hline \multirow{5}{*}{\multicolumn{2}{|c|}{ Constant orders }} & monthly \\
\hline & & Over 8/ year \\
\hline & & Over 4/ year \\
\hline & & Over $1 /$ year \\
\hline & & 0 \\
\hline \multirow{3}{*}{\multicolumn{2}{|c|}{ Usage of Apulum`s brand }} & Apulum \\
\hline & & Apulum + other brand \\
\hline & & $\begin{array}{l}\text { Other brand or without } \\
\text { brand }\end{array}$ \\
\hline
\end{tabular}

Every possibility of interpretation had a unique score. In order to find the customer satisfaction and confidence degree, the criteria mentioned in Table 2 were applied for all (internal and external) customers, individually, obtaining a score for each criterion, for each customer. Then, an average for each criterion was calculated for all internal and external customers considered in the case study. After that, the average obtained was used in a formula in order to calculate the degree of customer satisfaction and confidence. Figure 4 presents the results of the research. 


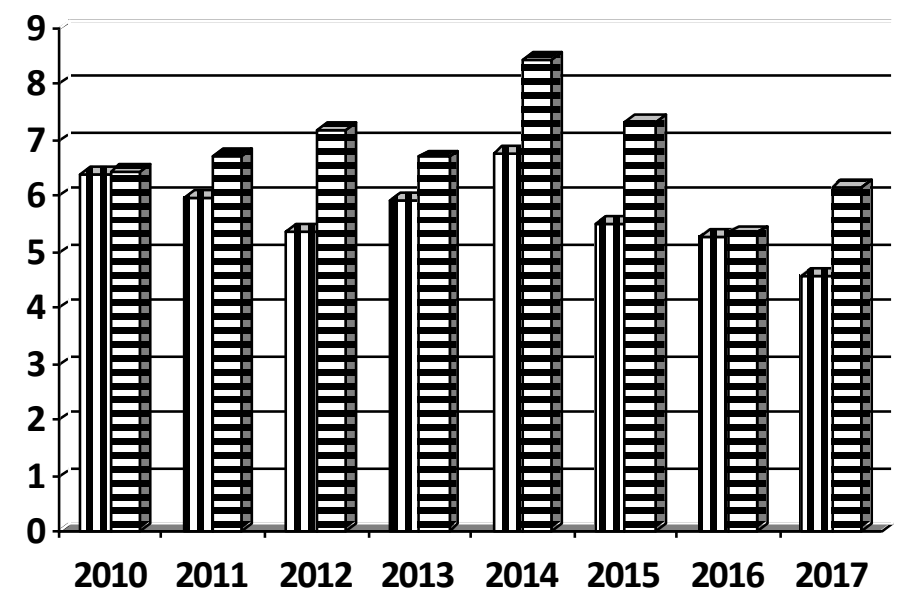

W External score 曰 Internal score

Figure 4: The degree of customer satisfaction and confidence (2010-2017)

The results shows that in the mentioned period the satisfaction and the confidence of the internal clients was higher than from the external clients, this may be due to the adaptation of the organization to the new customers' requirements, as well as on the strength of increasing the image of the organization on the internal market. The highest score obtained for external clients was 6.75 in 2014 and 8.43, also in the same year for internal cliens. The internal score was higher with 1.68 than the external score. This difference may be due to the evolution of clients business and duration of colaboration, because in the period considered the company won new external clients, so the duration of colaboration was lower from the external clients than from the internal clients. The lowest value was 4.56 in 2017 for external clients and 5.34 in 2016 for internal clients. In this situation, the external score was lower with 0.78 than the internal score.

In terms of the evolution of the external score during 2010-2012 there was a decrease, followed by an increase between 2013-2014 and another decrease in the last three years of the period considered. Regarding the internal score among 2010-2012 there was a growth, then in 2013 there was a fall, followed by an increase in 2014. In 2015-2016 there was a decrease of the internal score while in the last year there was a rise. These variations depend on the criteria considered. For example, if the external clients had relationships with other competing companies the score for this criterion was lower. Also, another criterion referred to the constant orders. It took into account only the frequency of orders and not the quantity of products ordered. Therefore, the external score was influenced by this criterion, because the external clients ordered a larger quantity of products with a lower frequency, while internal clients ordered a smaller quantity of products with a higher frequency. Also, another cause of the difference between the external and internal score was due to the fact that $100 \%$ of the internal clients used Apulum `s brand, while only $10 \%$ of the external clients used Apulum`s brand and $20 \%$ used Apulum`s brand and others brands.

\section{Conclusion}

The purpose of this paper is to identify the changes appeared in S.C. Apulum S.A due to the implementation of a quality management system based on ISO 9001 and to analyze the customer satisfaction and confidence. 
The situation shows that after the implementation of ISO 9001 the quality of the products and processes developed in the compay has increased considerable, thus influencing the overall success of business activities by improving the economic effects associated with quality.

The customer satisfaction and confidence analysis was obtained by applying the brainstorming technique in order to establish the criteria taken into account and the formula used to calculate the internal and external score. The results of the study indicate an irregular variation of customer satisfaction and confidence. Considering the criteria used in order to identify the internal and external score, it is normal to have different variations between the scores. Also, before the implementation of a quality management system in the company there was no situation regarding the customer satisfaction and confidence.

Likewise, there is a biunique relationship between improving the quality management system and assessing the customer satisfaction and confidence, because they are mutually conditioned. Also, the annual customer satisfaction and confidence assessment allow toidentify the quality management system processes that need to be improved.

\section{Acknowledgements}

This article is based on a contribution presented at the 9th edition of the International Conference of Doctoral Students and Young Researchers "Emerging Markets Economics and Business", Oradea, 21.11.2018, and represents an extended version of it.

\section{References}

Aggelogiannopoulos, D., Drosinos, E. H. and Athanasopoulos, P., 2007. Implementation of a quality management system (QMS) according to the ISO 9000 family in a Greek small-sized winery: A case study. Food Control, 18, pp. 1077-1085.

Apulum Porcelain Factory [online] Available at http://apulum.com/index.php/ro/despre-noi [accessed_29.10.2018].

Carey, R. B., 2018. What Is a Quality Management System, and Why Should a Microbiologist Adopt One?. Clinical Micobiology Newsletter, 40, pp. 183-189.

Hosam, A. S. and Shuhaila, H., 2018. A review of brainstorming techniques in higher education. Thinking Skills and Creativity, 27, pp. 78-91.

Hsu, C. C., Wang, T. I., Lin, K. J. and Chang, J. W., 2018. The effects of the alternate writing and sketching brainstorming method on the creativity of undergraduate industrial design students in Taiwan. Thinking Skills and Creativity, 29, pp. 131-141.

Ingason, H. T., 2015. Best Project Management Practices in the Implementation of an ISO 9001 Quality Management System. Procedia - Social and Behavioral Sciences, 194, pp. 192-200.

Krone, R., 2017. Not Just Guess Work: Tips for Observation, Brainstorming, and Prototyping. Techniques in Vascular and Interventional Radiology, 20, pp. 94-100.

Litcanu, M., Prostean, O., Oros, C. and Mnerie, A. V., 2015. Brain-Writing Vs. Brainstorming, Case Study For Power Engineering Education. Procedia - Social and Behavioral Sciences, 191, pp. 387-390.

Lukichev, S. and Romanovich, M., 2016. The Quality Management System as a Key Factor for Sustainable Development of the Construction Company. Procedia Engineering, 165, pp. 1717-1721.

Magd, H. and Nabulsi, F., 2012. The Effectiveness of ISO 9000 in an Emerging Market as a Business Process Management Tool: the case of the UAE. Procedia Economics and Finance, 3, pp.158-165.

Priede, J., 2012. Implementation of Quality Management System ISO 9001 in the World and its Strategic Necessity. Procedia - Social and Behavioral Sciences, 58, pp. 1466-1475. 
Refaat, R. and El-Henawy, I. M., 2018. Innovative method to evaluate quality management system audit results ' using single value neutrosophic number. Cognitive Systems Research, https://doi.org/10.1016/j.cogsys.2018.10.014

Santos, G., Costa, B. and Leal, A,. 2012. Motivation and benefits of implementation and certification according ISO 9001 - the Portuguese experience. International Journal of Engineering, Science and Technology, 6, pp. 1-12.

SES Quality [online] Available at https://sesquality.wordpress.com/2012/11/23/process-mappingmodeling/ [accessed 13.01.2018].

Sumaedi, S. and Yarmen, M., 2015. The Effectiveness of ISO 9001 Implementation in Food Manufacturing Companies: A Proposed Measurement Instrument. Procedia Food Science, 3, pp. 436-444.

Zainol, A. S., Azahari, M. H. H., Sanusi, Z. M. and Ramli, M., F., 2012. Improving Satisfaction: The Importance of Ownership of the Topic under the Group Brainstorming Technique. Procedia - Social and Behavioral Sciences, 50, pp. 513-524.

\section{Bio-note}

Ing. Sârb Adina is a PhD student in the Department of Engineering and Management at "Lucian Blaga" University of Sibiu, Romania. Also, she works as an engineer at S.C. Apulum S.A., Romania. Her research field includes integrated management systems (ISO 9001 QMS, ISO 14001 EMS and OHSAS 18001 OHSMS), quality techniques and instruments, engineering and quality management. She is currently doing a research on a thesis titled "Contributions regarding the improvement of the quality management system within the company titled S.C. Apulum S.A."

Dr. Ing. Itul Liliana is Quality manager at S.C. Apulum S.A., the Porcelain factory in Alba lulia. She is also external auditor for quality management system ISO 9001, trainer and assessor at the Agency for Payments and Social Inspection. Her PhD thesis is titled "Innovative engineering for sustainable product quality development with applicability in fine ceramic industry". She is coauthor in inventions and patented innovations and is currently involved in organizational sustainability and social accountability.

Dr. Ing. Popa Maria is Dean of the Faculty of Economic Sciences, "1 Decembrie 1918" University of Alba lulia. Also, she is professor at the same university. Her PhD thesis is titled "Research regarding the determination of environmental poluttion in Zlatna Area with heavy metals cations - Heavy metals contamination of agro-food goods". Her main research interests are: Basics of Merceology, Food and Non Food Merchology, Food Security, Food Quality and Safety, Goods Logistics, Environmental Chemistry, Waste Recovery and Recycling Technologies. 